\title{
Extraction and Physicochemical Characterization of Mucilage from Opuntia cochenillifera (L.) Miller
}

\author{
Mariel Monrroy, ${ }^{1,2}$ Erick García, ${ }^{1,2}$ Katherine Ríos, ${ }^{1,2}$ and José Renán García ${ }^{1,2}$ \\ ${ }^{1}$ Centro de Investigación en Bioquímica y Química Aplicada, Facultad de Ciencias Naturales y Exactas, \\ Universidad Autónoma de Chiriquí, David, Panama \\ ${ }^{2}$ Departamento de Química, Facultad de Ciencias Naturales y Exactas, Universidad Autónoma de Chiriquí, David, Panama
}

Correspondence should be addressed to José Renán García; joregam@gmail.com

Received 29 December 2016; Revised 1 April 2017; Accepted 10 April 2017; Published 10 May 2017

Academic Editor: Patricia Valentao

Copyright (C) 2017 Mariel Monrroy et al. This is an open access article distributed under the Creative Commons Attribution License, which permits unrestricted use, distribution, and reproduction in any medium, provided the original work is properly cited.

\begin{abstract}
The aim of this study was to extract mucilage from O. cochenillifera (L.) cacti and determine its functional and physicochemical properties. The best mucilage yield (31\%) was obtained by nonthermal extraction with hydration. The mucilage has appreciable carbohydrate and protein contents. The phytochemical analysis shown the presence of alkaloids and terpenes/steroids. The Fourier transformed infrared (FT-IR) spectrum of the mucilage exhibits typical bands for carbohydrates as $\mathrm{O}-\mathrm{H}, \mathrm{C}-\mathrm{H}$, and $-\mathrm{COO}^{-}$. The mucilage demonstrated water- and oil-holding capacities of $2.78 \mathrm{~g}$ water/g dry mucilage and $1.80 \mathrm{~g}$ oil/g dry mucilage, respectively, these properties can have a positive effect on the texture of the products when used as a stabilizer. The mildly acidic $\mathrm{pH}(4.8-5)$ contributes to its emulsifying capacity. The presence of electrolytes in the mucilage can be of great value in flocculation processes. The mucilage forms low viscosity solutions in the same manner as gum Arabic. Finally, its potential for use as a textile dye remover was evaluated, achieving a 70\% removal rate from aqueous solutions. The prepared mucilage exhibits properties that recommend it as a natural material that can be used as an additive in the chemical, food, pharmaceuticals and cosmetics industries, as well as in decontamination processes.
\end{abstract}

\section{Introduction}

Opuntia spp. are flowering plants belonging to the Cactaceae family. They grow naturally in tropical and semitropical regions [1], and their cultivation is well known, especially in Mexico, Argentina, Peru, Bolivia, Brazil, Chile, the United States (Texas), Spain, Italy, Africa (Morocco, Tunisia, Eritrea, and Ethiopia), Israel, and South Africa [2]. Traditionally, the Opuntia have been used for both medicinal and edible purposes. Research has shown that extracts from their pads can reduce cholesterol levels [3] and exhibit hypoglycemic effects [4], antiulcer activity [5], neuroprotective effects [6], and anti-inflammatory and analgesic properties $[5,7]$. Furthermore, these Cactaceae are characterized by their hydrocolloid properties, having a high capacity to retain water under adverse weather conditions due largely to one of their main functional components, mucilage $[1,2]$.

Mucilage is a complex polymeric substance composed mainly of carbohydrates with highly branched structures, which include L-arabinose, D-galactose, L-rhamnose, Dxylose, and galacturonic acid in various proportions [8]. It also contains glycoproteins [9] and other substances such as tannins, alkaloids, and steroids [1]. The mucilage composition differs among the various Opuntia spp. and the regions in which they grow $[1,2]$. In addition to the aforementioned medicinal activities for these cacti, which are associated with this complex material, the ability of mucilage to form molecular networks and retain large amounts of water makes it a potential source of hydrocolloids for the chemical and cosmetics industries. Several studies have evaluated its uses in water purification/filtration [2, 9], as an adhesive lime $\left[\mathrm{Ca}(\mathrm{OH})_{2}\right]$ [3], emulsifying agent [10], or flocculant [11], and as an enhancer of water infiltration in soils, due to its physical properties (viscosity, elasticity, texture, and emulsifier) [12]. Other mucilage applications include its use in foods as a stabilizer, flavoring agent, fat substitute [2], and edible coating to extend the useful life of fruit [13]. 
TABLE 1: Thermal extraction conditions for fresh and dried cladodesof $O$. cochenillifera.

\begin{tabular}{lcc}
\hline Experiment number & $\begin{array}{c}\text { Time } \\
(\mathrm{min})\end{array}$ & $\begin{array}{c}\text { Temperature } \\
\left({ }^{\circ} \mathrm{C}\right)\end{array}$ \\
\hline 1 & 60 & 50 \\
2 & 90 & 50 \\
3 & 60 & 80 \\
4 & 90 & 80 \\
5 & 54 & 65 \\
6 & 96 & 65 \\
7 & 75 & 44 \\
8 & 75 & 86 \\
9 & 75 & 65 \\
10 & 75 & 65 \\
11 & 75 & 65 \\
\hline
\end{tabular}

Most studies on the physical and chemical properties of Opuntia mucilage have focused on O. ficus-indica, and there is little scientific information on the characteristics of other Opuntia spp. such as O. cochenillifera. Among the meritorious attributes of $O$. cochenillifera are its hypoglycemic effects [4] and the ability to decolorize water [14]. Consequently, this research will focus on optimizing the extraction of the mucilage from O. cochenillifera (L.) Miller and its physicochemical characterization. The mucilage thus obtained could be a natural, economical alternative functional material for use in many industrial processes.

\section{Experimental}

2.1. Raw Material. Fresh cladodes of O. cochenillifera were harvested from Universidad Autónoma de Chiriquí-Panamá $\left(8^{\circ} 25^{\prime} 49.51^{\prime \prime} \mathrm{N}\right.$ y $\left.82^{\circ} 26^{\prime} 53.36^{\prime \prime} \mathrm{W}\right)$. The cladodes had an average size of $7.67 \mathrm{~cm} \times 18.15 \mathrm{~cm}$. Moisture content was determined after drying at $105^{\circ} \mathrm{C}$ for $24 \mathrm{~h}$. The specimen was identified by Professor Rafael Rincón at the Herbarium of Universidad Autónoma de Chiriquí (code: UCH). A voucher specimen (number: 006757) was deposited in the Herbarium.

\subsection{Extraction of Mucilage}

2.2.1. Thermal Extraction of Fresh Cladodes. The cladodes were peeled, cut into pieces $\left(2 \times 2 \mathrm{~cm}^{2}\right)$, crushed, and homogenized in a ratio of $7.5 \mathrm{~g}$ in $15 \mathrm{ml}$ distilled water. This ratio was equivalent to suspending $100 \mathrm{mg}$ dry basis in $5 \mathrm{ml}$ water. Samples were placed in a water bath at different temperatures for various reaction times (Table 1) and then filtered. The mucilage was precipitated by adding $45 \mathrm{~mL}$ ethanol and dried in an oven at $60^{\circ} \mathrm{C}$.

2.2.2. Thermal Extraction of Dried Cladodes. The cladodes were cut into pieces $\left(2 \times 2 \mathrm{~cm}^{2}\right)$, dried at $60^{\circ} \mathrm{C}$ for $48 \mathrm{~h}$, and milled. Then, the mucilage was extracted by mixing $100 \mathrm{mg}$ of the milled sample with $5 \mathrm{~mL}$ water for different temperatures $\left(44-86^{\circ} \mathrm{C}, T\right)$ and times (54-96 min, $t$ ) (Table 1).
The mucilage was precipitated by adding $15 \mathrm{~mL}$ ethanol and dried in an oven at $60^{\circ} \mathrm{C}$.

The influence of the variables $T$ and $t$ for both types of extraction was determined using response surface methodology (RSM) and multiple linear regression methods. The optimum conditions for extracting the mucilage were obtained as the maximum values of the response surface by the SIMPLEX method. The generation and evaluation of the experimental designs were carried out with the program Modde 7.0.0.1 (Umetrics, USA). Statistical validation was performed using one-way analysis of variance ANOVA with a confidence level of $95 \%$. The models obtained were based on a circumscribed central composite design made of a factorial design and star points.

2.2.3. Extraction by Hydration. A solution was prepared by mixing the milled sample $(100 \mathrm{mg})$ with water $(5 \mathrm{~mL})$ and allowing it to stand for $24 \mathrm{~h}$. Then, the solution was filtered and the mucilage was precipitated by adding $15 \mathrm{~mL}$ ethanol and dried in an oven at $60^{\circ} \mathrm{C}$.

2.2.4. Extraction by Agitation. A solution was prepared as described in the preceding section, stirred for $30 \mathrm{~min}$ using a magnetic stirrer, and then filtered. The mucilage was precipitated by adding $15 \mathrm{~mL}$ ethanol for $30 \mathrm{~min}$ and dried in an oven at $60^{\circ} \mathrm{C}$.

2.2.5. Extraction by Agitation and Hydration. In this extraction, the sample was hydrated and agitated as in the previous sections.

All extractions were performed in triplicate. The results were analyzed using ANOVA and Tukey's honest significant difference (HSD) multiple comparison test $(p \leq 0.05)$.

2.3. Chemical Characterization of the Mucilage. The total carbohydrate content was determined by the phenol-sulfuric acid method, and the visible absorption of the resulting solution was measured at $490 \mathrm{~nm}$ (modified method of Bartkiene [15]). For the quantitative carbohydrate determination, mucilage powder $(100 \mathrm{mg})$ and $2.5 \mathrm{~N} \mathrm{HCl}(5 \mathrm{~mL})$ were mixed in a test tube and placed in a water bath at $95^{\circ} \mathrm{C}$ for $3 \mathrm{~h}$. The solution was neutralized with sodium carbonate, diluted with water $(5 \mathrm{~mL})$, and centrifuged. The supernatant was brought to a volume of $100 \mathrm{~mL}$. Then, a portion of the sample $(0.1 \mathrm{~mL})$ was added to $5 \%$ phenol $(1 \mathrm{~mL})$ and concentrated sulfuric acid $(5 \mathrm{~mL})$, vortexed for $1 \mathrm{~min}$, and placed in a water bath at $30^{\circ} \mathrm{C}$ for $20 \mathrm{~min}$. Finally, the total carbohydrate content was determined by visible spectrophotometry (Vis) at a wavelength of $490 \mathrm{~nm}$ and quantified against a calibration curve using glucose. The total nitrogen concentration in the mucilage was determined by the Kjeldahl method. The mineral contents were quantified by atomic absorption spectroscopy. All analyses were performed in triplicate.

The mucilage was subjected to a phytochemical screening using the following tests: the Salkowski test for sterols; the Shinoda and sodium hydroxide tests for flavonoids; the Dragendorff, Wagner, and Mayer tests for alkaloids; the 
ferric chloride test for tannins; the Rosenthaler test for saponins; and the Dimroth test for 5-hydroxy flavones. A thin-layer chromatography (TLC) was used in the analysis of alkaloids. TLC was performed on $10 \times 3 \mathrm{~cm}$ silica gel plates with a fluorescent indicator at $254 \mathrm{~nm}$ (Applichem, USA). Chloroform/methanol (9:1), chloroform (100\%), and ethyl acetate/methanol/chloroform/hexane $(6: 1: 2: 1)$ were used as mobile phases. Mucilage sample was dissolved in methanol/chloroform (1:1), macerated for 24 hours, and then centrifuged. Solution $(25 \mu \mathrm{L})$ was carefully layered at $1 \mathrm{~cm}$ from the bottom of the plate. After the separation, plates were dried at $60^{\circ} \mathrm{C}$ for $5 \mathrm{~min}$. Then drying, the spots on the developed plates were visualized at $254 \mathrm{~nm}$ and also revealed with Dragendorff and Wagner reagents. A meter rule was used to measure the distance moved by the solvent and distance moved by spot, from which the retention factor (Rf values) of the spots was calculated.

Infrared spectra of the mucilage were measured by direct transmittance using the $\mathrm{KBr}$ pellet technique. Spectra were recorded between 4000 and $500 \mathrm{~cm}^{-1}$, using a Shimadzu IRAffinity-1 Fourier-transform infrared spectrometer (FTIR) equipped with a deuterated L-alanine doped triglycine sulfate (DLATGS) detector. The background used for the FTIR measurements was a $\mathrm{KBr}$ pellet that contained no sample. All spectra were measured at a spectral resolution of $2 \mathrm{~nm}$ and 32 scans were taken per sample.

2.4. Physical Characterization of the Mucilage. The conductivity, $\mathrm{pH}$, density, and viscosity were determined in mucilage solutions of 1,4 , and $6 \%(\mathrm{w} / \mathrm{v})$, prepared by dissolving the mucilage powder in distilled water. Conductivity was determined using a conductometer and the $\mathrm{pH}$ with a $\mathrm{pH}$ meter (Mettler-Toledo, USA). The density was determined using a glass pycnometer. The viscosity of the samples, measured with a calibrated Cannon-Fenske glass capillary viscometer (Cannon Instrument Co., State College, PA, USA), was determined as the time required for the sample to flow under gravity through the device. All tests were performed in triplicate.

The water-holding capacity (WHC) and oil-holding capacity (OHC) were determined according to the methods of Chau et al. [16] and Thanatcha and Pranee [17]. A mucilage powder sample $(0.2 \mathrm{~g})$ was mixed in $10 \mathrm{~mL}$ distilled water or olive oil by vortexing for $1 \mathrm{~min}$ and centrifuged at $2200 \mathrm{rpm}$ for $30 \mathrm{~min}$. Then, the supernatant was removed and weighed. The WHC was expressed as the grams water held per gram sample, and the $\mathrm{OHC}$ as the grams oil held per gram sample.

2.5. Decolorization of a Textile Dye Solution. Different amounts of mucilage $(0.1,0.2$, or $0.3 \mathrm{~g})$ were mixed with separate green and blue dye solutions $(10 \mathrm{~mL}, 100 \mathrm{ppm}$, Dylon Fabric Dye) by vortexing for $3 \mathrm{~min}$ and then centrifuged at $3000 \mathrm{rpm}$ for $5 \mathrm{~min}$. The supernatants were removed and subjected to absorbance measurements by Vis spectrophotometry at $586 \mathrm{~nm}$ (green) and $400 \mathrm{~nm}$ (blue). The percentage removal of the dye solution was then determined.
TABLE 2: Mucilage yields from O. cochenillifera obtained via thermal extraction.

\begin{tabular}{lcc}
\hline Experiment number & $\begin{array}{c}\text { Yield } \\
(\%)^{\mathrm{a}}\end{array}$ & $\begin{array}{c}\text { Yield } \\
(\%)^{\mathrm{b}}\end{array}$ \\
\hline 1 & 21.7 & 27.4 \\
2 & 23.8 & 29.0 \\
3 & 23.3 & 24.0 \\
4 & 22.1 & 13.2 \\
5 & 23.6 & 21.1 \\
6 & 24.6 & 19.6 \\
7 & 22.1 & 33.0 \\
8 & 22.3 & 27.2 \\
9 & 21.9 & 24.1 \\
10 & 21.8 & 20.5 \\
11 & 22.4 & 21.1 \\
\hline
\end{tabular}

${ }^{a}$ Fresh cladodes.

${ }^{\mathrm{b}}$ Dried cladodes.

\section{Results and Discussion}

The mucilage content in a cladode is directly related to the moisture content because its heteropolysaccharide components have the ability to absorb water. In this work, the moisture content in young cladodes was higher than in older cladodes; thus, young cladodes with an average size of $7.67 \mathrm{~cm} \times 18.15 \mathrm{~cm}$ were employed. The moisture content in the fresh cladodes of $O$. cochenillifera is $92 \%$.

As mentioned earlier, mucilage could be a natural, economical alternative material for many industrial processes; therefore, an investigation of extraction process efficiency is relevant. Different extraction processes were examined, such as thermal and nonthermal extraction (hydration and agitation).

3.1. Mucilage Extraction. The mucilage yields obtained from fresh and dried cladodes using thermal extraction varied from 22 to $25 \%$ and 20 to $33 \%$ on a dry matter basis (Table 2), respectively. From the experimental design data and mucilage percentage obtained under each condition (Table 4), quadratic polynomials were determined (see (1)) for the fresh and dried cladodes, respectively, and validated by the ANOVA test.

$$
\begin{aligned}
\text { Mucilage }(\text { fresh, \%) }= & 22.0 \pm 0.3+0.3 \pm 0.2 t+0.02 \\
& \pm 0.2 T+0.7 \pm 0.2 t^{2}-0.7 \\
& \pm 0.3 t T
\end{aligned}
$$

Mucilage $($ dried, \%) $=21.3 \pm 1.5-2.1 \pm 1.3 T+4.6$

$$
\pm 1.4 T^{2}
$$

where $t$ is time and $T$ temperature.

In the case of the fresh cladodes, the linear term for time has a positive coefficient, meaning that the mucilage extraction increases with time. The positive quadratic terms indicates that large variation of time in either direction 


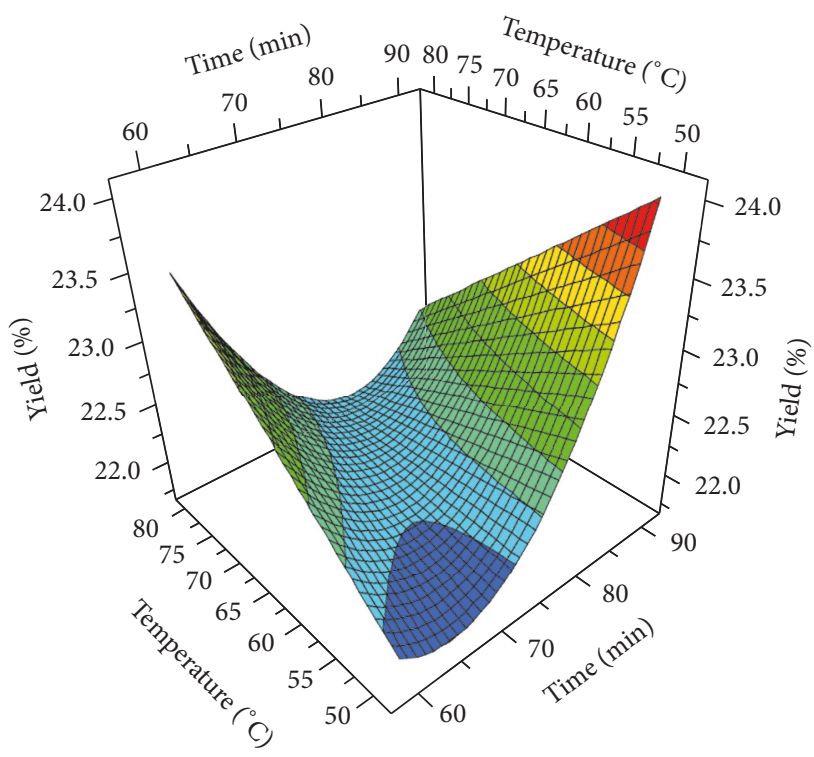

(a)

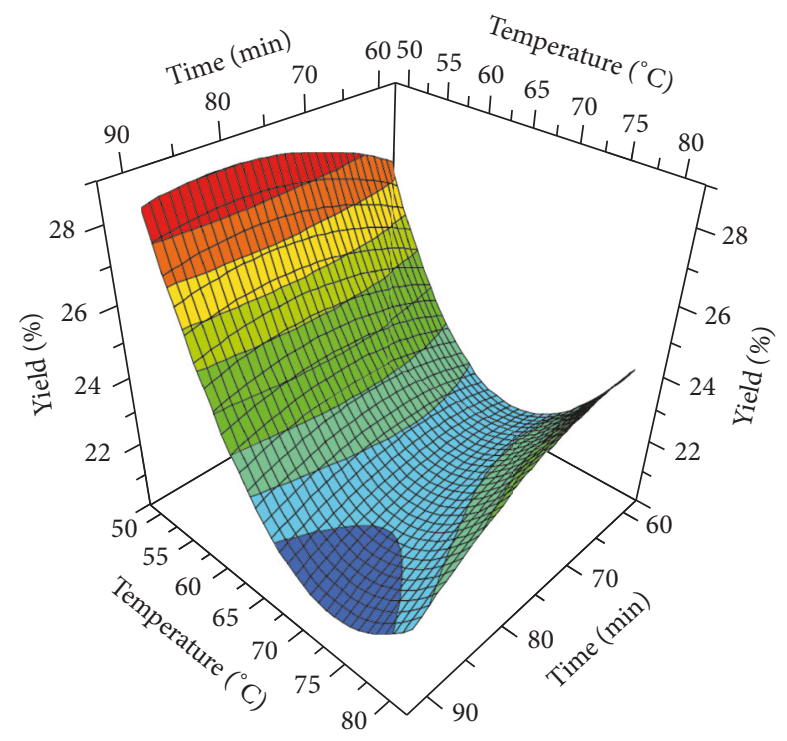

(b)

FIGURE 1: Response surfaces for removal of mucilage extracted from O. cochenillifera: (a) fresh cladodes and (b) dry cladodes.

will result in extraction yield increase (the response surface shows a minimum). However, the linear term for temperature has no effect on mucilage yield, but considering the confidence intervals, the interaction between both variables has a significant effect on mucilage extraction. For the dried cladodes, the linear term for the temperature has a negative coefficient, meaning that the extraction yield increased as the temperature declined. The positive quadratic terms indicates that large variation of temperature in either direction will result in extraction yield increase. Time appears to have no significant effect on mucilage extraction for the range studied (50-80 min). Considering the confidence intervals, the interactions between variables have no significant effect on mucilage extraction.

Error values corresponded to a $95 \%$ confidence level. The effects of the extraction conditions on the mucilage yield are shown in the response surface graph for the polynomials (within the studied variable ranges) (Figures 1(a) and 1(b)). The responses are close to the experimental values, with correlation coefficients $\left(r^{2}\right)$ of 0.93 and 0.89 for the fresh and dry cladodes, respectively.

The optimum values of the variables for the maximal mucilage yields were determined by the SIMPLEX method using the maximum values of the response surface. The maximum mucilage yields predicted for the fresh and dried cladodes are $24.5 \pm 0.3 \%$ and $34 \pm 1 \%$. The predicted values of the best extraction variables are $54 \mathrm{~min}$ and $80^{\circ} \mathrm{C}$ for the fresh cladodes and $86 \mathrm{~min}$ and $44^{\circ} \mathrm{C}$ for the dried cladodes. The experimental mucilage yields for the fresh and dried cladodes obtained under these conditions are $24 \pm 1 \%$ and $31 \pm 2 \%$, respectively, which agree well with the predicted values. Mucilage extraction from the dried cladodes was better than from the fresh cladodes, which may be related to the larger surface area of the former, which would improve the extraction process.
TABLE 3: Mucilage yields via nonthermal extraction from $O$. cochenillifera cladodes.

\begin{tabular}{lc}
\hline Treatment & Yield (\%) \\
\hline Hydration & $31 \pm 1$ \\
Agitation & $26.4 \pm 0.1$ \\
Hydration and agitation & $31 \pm 2$ \\
\hline
\end{tabular}

TABLE 4: Mineral content of mucilagefrom O. cochenillifera.

\begin{tabular}{lcccc}
\hline $\mathrm{N}$ & $\mathrm{P}$ & $\mathrm{K}$ & $\mathrm{Ca}$ & $\mathrm{Mg}$ \\
\hline 1.6 & 0.4 & 1.2 & 1.8 & 0.3 \\
\hline $\mathrm{Fe}$ & $\mathrm{Cu}$ & $\begin{array}{c}\mathrm{Mn} \\
\mathrm{Mg} \cdot \mathrm{kg}^{-1}\end{array}$ & $\mathrm{Zn}$ & $\mathrm{Na}$ \\
\hline 191 & 424 & 344 & 386 & 250 \\
\hline
\end{tabular}

The nonthermal methods of extraction from the cladodes were based on hydration, agitation, and hydration and agitation processes. Table 3 shows the mucilage yields obtained for the three approaches. Increased performance is observed for the samples subjected to the hydration and hydration/agitation processes, compared to agitation alone. This indicates that the hydration process is very important when mucilage extraction is performed with previously dried and powdered cladode samples. The results obtained were analyzed using ANOVA and Tukey's HSD multiple comparison test ( $p \leq 0.05$ ), which showed that there is a significant difference between the mean of the agitation process with the other two processes at the $95 \%$ confidence level.

The maximum mucilage extraction yields obtained from cladodes under the thermal and nonthermal extraction methods in this study are similar and/or higher than those reported for other Opuntia such as O. streptacantha (7.2\%), 
TABLE 5: Phytochemical analysis of $O$. cochenillifera mucilage.

\begin{tabular}{lcc}
\hline Metabolite & Test & Mucilage \\
\hline \multirow{3}{*}{ Alkaloids } & Meyer & $(+)$ \\
& Dragendorff & $(+)$ \\
& Wagner & $(+)$ \\
\hline Saponins & Rosenthaler & $(-)$ \\
\hline Tannins & $\mathrm{FeCl}_{3}$ & $(-)$ \\
\hline Terpenes/steroids & Salkowski & $(+)$ \\
\hline \multirow{2}{*}{ Flavonoids } & Reaction with $\mathrm{NaOH}$ & $(-)$ \\
& Shinoda & $(-)$ \\
\hline 5-hydroxy flavones & Dimroth & $(-)$ \\
\hline
\end{tabular}

O. megacantha (7.4\%), O. albicarpa (6.9\%), O. milpa alta (7\%), O. dillenii (16\%), and O. ficus-indica (4-25\%) [8, 18-20].

3.2. Chemical Characterization of the Mucilage. The total carbohydrate content was $40 \%$, which is higher than that reported for $O$. dillenii, with 12 to $15 \%$ as polysaccharides [20], but within the range given for O. ficus-indica (13-64\%) $[21,22]$. In addition, the mucilage is an excellent source of essential minerals such as calcium, phosphorus, magnesium, iron, potassium, zinc, and copper (Table 4). Calcium is the most abundant mineral in the mucilage, which agrees with other studies of cactus pads [23-25]. For example, O. ficusindica was a better source of calcium than spinach, soy, and grains, suggesting that Opuntia spp. may have potential in the prevention and treatment of diseases such as osteoporosis [26]. Because of their excellent nutritional qualities, Opuntia (especially $O$. indica) have been used as food sources in countries such as Mexico. As the $O$. cochenillifera mucilage is a rich source of carbohydrates and essential minerals, it has good potential for use as a nutritional supplement.

The crude protein content was determined as $7.4 \%$. This value is comparable to those reported for O. ficus-indica cladodes (5-9\%) but higher than those in O. stricta (5\%) and guar gum $(3-5 \%)[1,27,28]$. The interactions that occur through the specific (hydrophilic) functional groups of polysaccharides and proteins are an important factor in the study of mucilage proteins; these form a three-dimensional network that can improve the stability and uniformity of the system matrix and suggest potential application in the industry [29]. Usually, proteins and polysaccharides are safe food additives that can form physically stable emulsions [30].

The phytochemical analysis shown in Table 5 reveals the presence of alkaloids by the Dragendorff, Mayer, and Wagner tests, which identify quaternary alkaloids and/or amine-oxides. The TLC analysis also revealed the presence of alkaloids; two spots were visualized at $254 \mathrm{~nm}$ (Figure 2), using different mixtures of eluents. Ethyl acetate/methanol/ chloroform/hexane $(6: 1: 2: 1)$ is the best eluent employed, showing Rf values 0.88 and 0.63 , respectively (Table 6 ). Likewise, two spots were observed with Dragendorff and Wagner reagents. The presence of terpenes/steroids was also found using the Salkowski test. Although the presence of saponins, flavonoids, and tannins was not found in this study, Tomás $\mathrm{Ch}$ et al. [31] reported the presence of saponins, flavonoids,

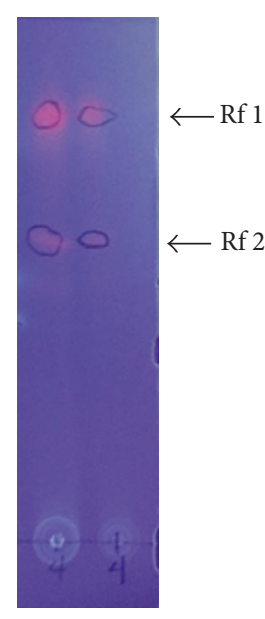

FIGURE 2: TLC based detection of alkaloids of O. cochenillifera mucilage extracts visualized under UV at $254 \mathrm{~nm}$.

and alkaloids in the pulp of O. ficus-indica. The chemical composition of the Opuntia spp. is quite variable, depending on a number of factors such as the chemical characteristics of the soil, geographical location, environmental conditions, age, and species $[8,22,27]$.

The FT-IR spectrum of the mucilage exhibits typical bands for Opuntia spp. The functional group bands found in the $O$. cochenillifera mucilage (Figure 3 ) are characteristic for proteins and polysaccharides. The bands at 3420, 2931, and $1623 \mathrm{~cm}^{-1}$ represent the stretching vibrations of $\mathrm{O}-\mathrm{H}, \mathrm{C}-\mathrm{H}$, and $-\mathrm{COO}^{-}$(asymmetric vibrations) groups, respectively, in carbohydrate and uronic acid molecules. Further, the bands at 2931 and $1623 \mathrm{~cm}^{-1}$ appear to be associated with the $\mathrm{N}-\mathrm{H}$ stretching and bending motions, respectively, of proteins. Han et al. [20] and Contreras-Padilla et al. [18] reported bands at $3500-3200 \mathrm{~cm}^{-1}$ corresponding to carbohydrate $\mathrm{O}-\mathrm{H}$ bonds in O. dillenii and O. ficus-indica mucilage. Also, they assigned a band around $2920 \mathrm{~cm}^{-1}$ to the $\mathrm{C}-\mathrm{H}$ stretching vibration of the pyranose group. Zhao et al. [32] attributed the bands at 1620,1596 , and $1420 \mathrm{~cm}^{-1}$ to deprotonated carboxylic acid groups $\left(-\mathrm{COO}^{-}\right)$in uronic acid in $\mathrm{O}$. monacantha. Similar bands are observed at 1623,1582 , and $1431 \mathrm{~cm}^{-1}$ in our spectrum. The bands found at $\sim 1431-1264 \mathrm{~cm}^{-1}$ can be assigned to $\mathrm{C}-\mathrm{O}$ stretching and $\mathrm{O}-\mathrm{H}$ deformation vibrations, according to Han et al. [20] and the bands at $1431-1393 \mathrm{~cm}^{-1}$ indicate $\mathrm{C}-\mathrm{N}$ stretching modes [33]. The bands at 1085 and $1045 \mathrm{~cm}^{-1}$ indicate the presence of monosaccharides such as mannose and glucose in pyranose ring conformations [20, 34]. The absorption band at $893 \mathrm{~cm}^{-1}$ corresponds to $\beta$-Dglucose [32]. The bands at 774 and $608 \mathrm{~cm}^{-1}$ are attributed to $\mathrm{N}-\mathrm{H}$ and $\mathrm{O}-\mathrm{H}$ out-of-plane vibrations, respectively $[32,33]$.

\subsection{Physical Characterization of the Mucilage}

3.3.1. pH, Conductivity, Density, and Viscosity Measurements. The functional properties of mucilage can be affected by its chemical composition. The mucilage densities at concentrations of 1,4 , and $6 \%$ are $1.03,1.03$, and $1.05 \mathrm{~g} \cdot \mathrm{mL}^{-1}$, 
TABLE 6: Alkaloids analysis of O. cochenillifera mucilage by TLC.

\begin{tabular}{lcccc}
\hline Eluent & Number of spots detected & Rf 1 & Rf 2 & Observation \\
\hline Chloroform/methanol $(9: 1)$ & 2 & 0.70 & 0.93 & Brown spots with Dragendorff \\
Chloroform (100\%) & 2 & 0.70 & 0.82 & and Wagner reagent; fluoresced \\
Ethyl acetate/methanol/chloroform/hexane $(6: 1: 2: 1)$ & 2 & 0.63 & 0.88 & violet light at 254 nm. \\
\hline
\end{tabular}

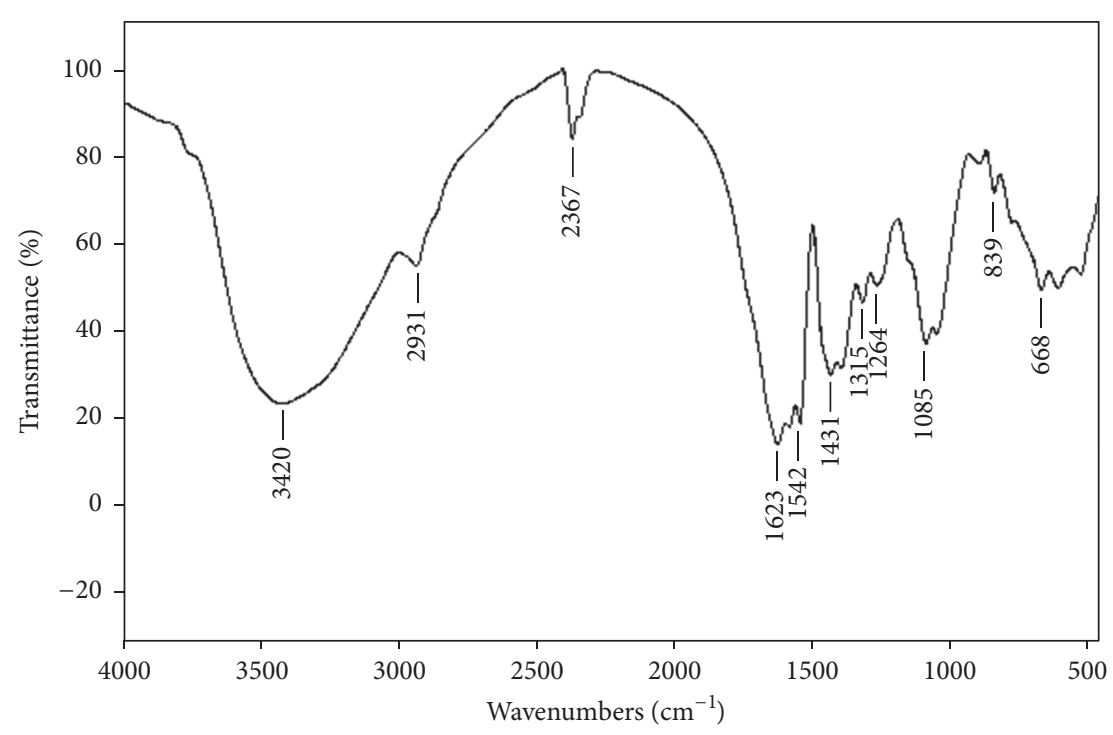

FIGURE 3: FT-IR spectrum of $O$. cochenillifera mucilage.

respectively. These values are higher than those reported for O. ficus-indica $\left(0.85 \mathrm{~g} \cdot \mathrm{mL}^{-1}\right)$ and O. stricta $\left(0.81 \mathrm{~g} \cdot \mathrm{mL}^{-1}\right)$ at concentrations of $8 \%$ [1]. However, the density obtained for the $O$. cochenillifera mucilage is comparable to those reported for gum arabic $\left(1.00-1.02 \mathrm{~g} \mathrm{~mL}^{-1}\right)$ at the same concentrations [35]. Gum arabic is the most utilized type of gum in food and other industrial applications because of its good emulsifying and stabilizing properties.

The conductivities of the obtained mucilage solutions are lower than those reported in the literature for O. ficusindica but comparable to O. stricta [1]. The conductivity values for samples prepared at concentrations of 1,4 , and $6 \%$ are $2.3,4.9$, and $6.4 \mathrm{mS} \mathrm{cm}^{-1}$, respectively. Variations in the conductivity at different concentrations may be attributed to the presence of greater numbers of divalent and monovalent ions, which increase the conductivity, as has been reported for the O. ficus-indica mucilage [1]. According to Gebresamuel and Gebre-Mariam [1], the presence of electrolytes in the mucilage can be of value in the flocculation of suspension formulations.

The $\mathrm{pH}$ measurements reveal that the mucilage at different concentrations is slightly acidic (4.8-5.0). This acidic nature indicates that the mucilage contains uronic acids in its structure. The $\mathrm{pH}$ values are lower than those found by Contreras-Padilla et al. [18] for O. ficus-indica (5.5-6) but comparable to those reported for gum arabic (4.5-5.6) [36, 37]. The $\mathrm{pH}$ is also a critical factor in coagulation/flocculation processes, wherein the optimal $\mathrm{pH}$ should be between 5 and $7.5[38]$.
The mucilage viscosities for solutions of 1 and $4 \%$ are 1.6 and $4.6 \mathrm{mPa} \cdot \mathrm{s}$, respectively. These values are comparable to those for 1 and $4 \%$ solutions of pure gum arabic (1.3 and $2.4 \mathrm{mPa} \cdot \mathrm{s}$, resp.) [35]. This ability of mucilage to form low viscosity solutions at low concentrations in the same manner as gum arabic should enable it to form solutions in a wide range of concentrations with excellent properties as an emulsifier and stabilizer.

3.3.2. Water- and Oil-Holding Capacities. O. cochenillifera mucilage presents a better WHC $(2.78 \mathrm{~g}$ water/g dry mucilage) than $\mathrm{OHC}(1.80 \mathrm{~g}$ oil/g dry mucilage). The WHC influences the formation of viscous solutions that can facilitate industrial processes. Mucilage forms a threedimensional network in contact with water, trapping it and resulting in highly viscous solutions. Mucilage is primarily composed of galactose, mannose, xylose, and other sugars, and, thus, has a high capacity to bind or retain water, similarly to pectins, gums, and some algal polysaccharides. Because of this large water absorption capacity, mucilage may find applications in foods, cosmetics, and pharmaceuticals, in which it can dissolve, be dispersed, and form colloids [13]. Similarly, mucilage can be used to modify the rheological properties of soil, acting as a binding agent in soil aggregation $[2,12]$. The $\mathrm{OHC}$ would allow its use in combination with other products to collect petroleum and various oils in case of spills on water. In addition, the good $\mathrm{OHC}$ value suggests that mucilage could improve the texture of food products. 


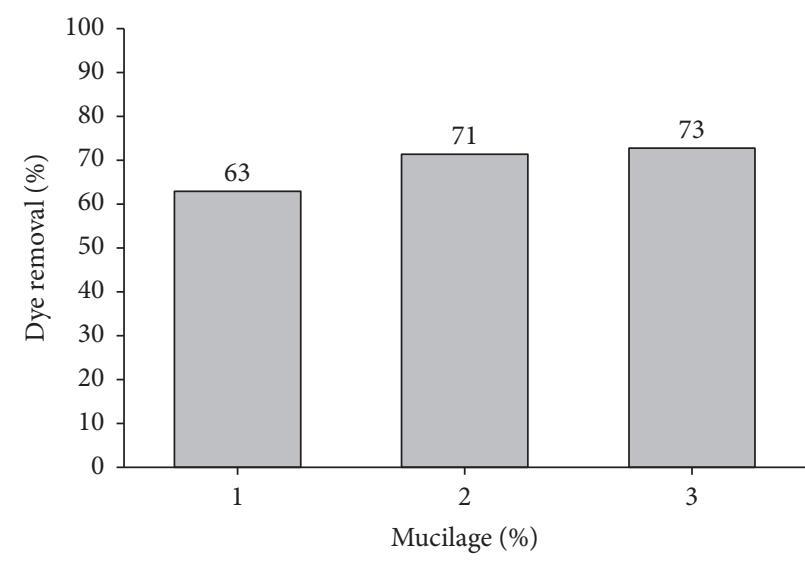

(a)

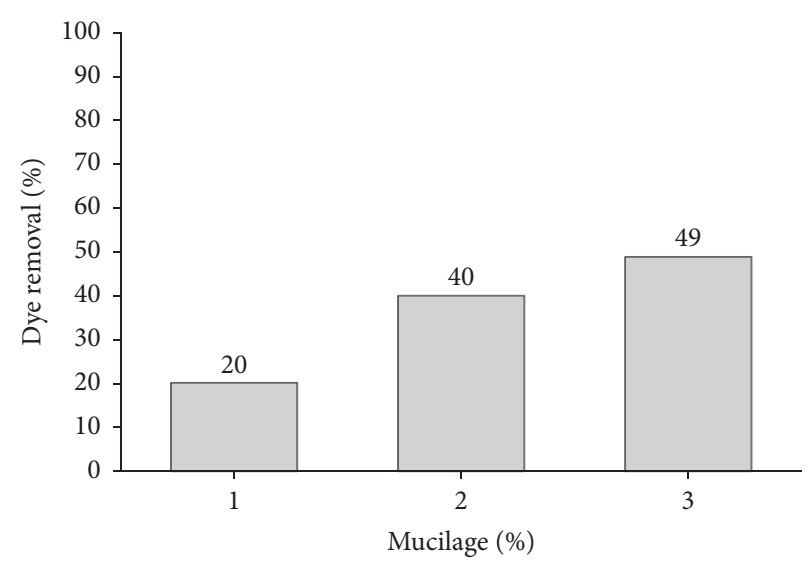

(b)

FIGURE 4: Removal of textile dyes at different concentrations of mucilage: (a) green dye and (b) blue dye.

3.4. Removal of Textile Dyes as a Sample Application. Mucilage has the potential to be used in the clarification of water due to its ability to retain different types of particles that are dispersed therein [9]. Additionally, as a negatively charged polyelectrolytic molecule due mainly to its sugar composition, mucilage has the ability to attract or retain certain types of positively charged substances. As demonstrated in this investigation, the capacity of the $O$. cochenillifera mucilage to remove textile dyes from aqueous solutions is considerable (Figures 4(a) and 4(b)). The removal percentage varied depending on the mucilage concentration and the dye, with maximum values of $73 \%$ and $49 \%$ for the green and blue dyes, respectively, at a concentration of $3 \%$ mucilage. These results agree with those reported by Peláez-Cid et al. [39] in which 5-95\% of the textile dyes were removed from aqueous solutions using O. ficus-indica fruit waste as an adsorbent. According to Anjaneyulu et al. [40] adsorption methods for the removal of dyes are based on the high affinity of the dyes. Adsorptive bleaching is influenced by several factors, such as the physicochemical dye-adsorbent interactions, adsorbent surface area, particle size, temperature, and contact time.

O. cochenillifera mucilage can be considered a low-cost biosorbent and environmentally friendly alternative for water clarification. For example, the textile industry worldwide consumes tremendous amounts of water in dyeing processes, and wastewaters from this industry are some of the most polluted across all industrial sectors. Some dyes and byproducts are carcinogens or mutagens and aesthetically deteriorate water bodies and impact flora and fauna. Zhang et al. [41] compared the ability of a mucilage clarifier with other traditional agents such as aluminum sulfate, reporting that the mucilage of O. ficus-indica demonstrated similar behavior to aluminum sulfate.

\section{Conclusion}

O. cochenillifera mucilage is a functional plant-derived material that has potential applications in the pharmaceutical and chemical industries. It is a rich source of carbohydrates, proteins, and minerals and can be considered nontoxic and safe for humans. Indeed, several cultures have traditionally used the cladodes of the Opuntia spp. as food. Its density, viscosity, $\mathrm{pH}$, and conductivity characteristics recommend its use as an additive in the formulation of food and drugs. $O$. cochenillifera mucilage could be a good alternative emulsifier and stabilizing agent. Finally, the mucilage from $O$. cochenillifera could be considered a natural technological alternative in many processes of decontamination for its ability to remove dyes.

\section{Conflicts of Interest}

The authors declare that they have no conflicts of interest.

\section{Acknowledgments}

Financial support was received from National Secretariat of Science, Technology, and Innovation (SENACYT) as member of the Panamá Research National System (SNI). The authors would like to thank staff at the Herbarium of Universidad Autónoma de Chiriquí (UNACHI) for the identification of the Opuntia sp. and Dr. Viviana Morales of the Research Center for Natural Products and Biotechnology of UNACHI for her support with the analysis of alkaloids.

\section{References}

[1] N. Gebresamuel and T. Gebre-Mariam, "Comparative physicochemical characterization of the mucilages of two cactus pears (Opuntia spp.) obtained from Mekelle, Northern Ethiopia," Journal of Biomaterials and Nanobiotechnology, vol. 3, pp. 7986, 2012.

[2] C. Sáenz, E. Sepúlveda, and B. Matsuhiro, "Opuntia spp. mucilage's: a functional component with industrial perspectives," Journal of Arid Environments, vol. 57, no. 3, pp. 275-290, 2004.

[3] A. Cárdenas, W. M. Arguelles, and F. M. Goycoolea, "On the possible role of opuntia ficus-indica mucilage in lime mortar performance in the protection of historical buildings," Journal 
of the Professional Association for Cactus Development, vol. 3, 1998.

[4] A. Andrade-Cetto and M. Heinrich, "Mexican plants with hypoglycaemic effect used in the treatment of diabetes," Journal of Ethnopharmacology, vol. 99, no. 3, pp. 325-348, 2005.

[5] E. M. Galati, M. T. Monforte, M. M. Tripodo, A. D’Aquino, and M. R. Mondello, "Antiulcer activity of Opuntia ficus indica (L.) Mill. (Cactaceae): ultrastructural study," Journal of Ethnopharmacology, vol. 76, no. 1, pp. 1-9, 2001.

[6] H. Dok-Go, K. H. Lee, H. J. Kim et al., "Neuroprotective effects of antioxidative flavonoids, quercetin, (+)-dihydroquercetin and quercetin 3-methyl ether, isolated from Opuntia ficusindica var. saboten," Brain Research, vol. 965, no. 1-2, pp. 130-136, 2003.

[7] J. F. Loro, I. Del Rio, and L. Pérez-Santana, "Preliminary studies of analgesic and anti-inflammatory properties of Opuntia dillenii aqueous extract," Journal of Ethnopharmacology, vol. 67, no. 2, pp. 213-218, 1999.

[8] E. Sepúlveda, C. Sáenz, E. Aliaga, and C. Aceituno, "Extraction and characterization of mucilage in Opuntia spp.," Journal of Arid Environments, vol. 68, no. 4, pp. 534-545, 2007.

[9] T. Pichler, K. Young, and N. Alcantar, "Eliminating turbidity in drinking water using the mucilage of a common cactus," Water Science \& Technology, vol. 12, no. 2, pp. 179-186, 2012.

[10] N. Garti, "Hydrocolloids as emulsifying agents for oil-in-water emulsions," Journal of Dispersion Science and Technology, vol. 20, no. 1-2, pp. 327-355, 1999.

[11] K. A. Young, A. Anzalone, T. Pichler, M. Picquart, and N. A. Alcantar, "The mexican cactus as a new environmentally benign material for the removal of contaminants in drinking water," MRS Online Proceedings Library, vol. 930, 2006.

[12] D. Gardiner, P. Felker, and T. Carr, "Cactus extract increases water infiltration rates in two soils," Communications in Soil Science and Plant Analysis, vol. 30, no. 11-12, pp. 1707-1712, 1999.

[13] V. Del-Valle, P. Hernández-Muñoz, A. Guarda, and M. J. Galotto, "Development of a cactus-mucilage edible coating (Opuntia ficus indica) and its application to extend strawberry (Fragaria ananassa) shelf-life," Food Chemistry, vol. 91, no. 4, pp. 751-756, 2005.

[14] J. Jiménez, M. Vargas, and N. Quirós, "Estimation of the nopal cactus (Opuntia cochenillifera) for color removal in drinking water," Tecnología en Marcha, vol. 25, no. 4, pp. 55-62, 2012.

[15] E. Bartkiene, Método Fenol-Ácido Sulfúrico Plant Food Analysis Methods Kaunas, Lituania, Unión Europea, Kaunas, Lituania, 2012.

[16] C.-F. Chau, P. C. K. Cheung, and Y.-S. Wong, "Functional properties of protein concentrates from three chinese indigenous legume seeds," Journal of Agricultural and Food Chemistry, vol. 45, no. 7, pp. 2500-2503, 1997.

[17] R. Thanatcha and A. Pranee, "Extraction and characterization of mucilage in ziziphus mauritiana lam," International Food Research Journal, vol. 18, pp. 201-212, 2011.

[18] M. Contreras-Padilla, M. E. Rodríguez-García, E. GutiérrezCortez, M. d. C. Valderrama-Bravo, J. I. Rojas-Molina, and E. M. Rivera-Muñoz, "Physicochemical and rheological characterization of Opuntia ficus mucilage at three different maturity stages of cladode," European Polymer Journal, vol. 78, pp. 226234, 2016.

[19] L. Felkai-Haddache, F. Dahmoune, H. Remini, K. Lefsih, L. Mouni, and K. Madani, "Microwave optimization of mucilage extraction from Opuntia ficus indica Cladodes," International Journal of Biological Macromolecules, vol. 84, pp. 24-30, 2016.
[20] Y.-L. Han, J. Gao, Y.-Y. Yin, Z.-Y. Jin, X.-M. Xu, and H.-Q. Chen, "Extraction optimization by response surface methodology of mucilage polysaccharide from the peel of Opuntia dillenii haw. fruits and their physicochemical properties," Carbohydrate Polymers, vol. 151, pp. 381-391, 2016.

[21] J. H. Cota-Sánchez, "Nutritional composition of the prickly pear (Opuntia ficus-indica) fruit," in Nutritional Composition of Fruit Cultivars, M. S. J. Simmonds and V. R. Preedy, Eds., chapter 28, pp. 691-712, Academic Press, San Diego, Calif, USA, 2016.

[22] T. Nharingo and M. Moyo, "Application of Opuntia ficus-indica in bioremediation of wastewaters. A critical review," Journal of Environmental Management, vol. 166, pp. 55-72, 2016.

[23] L. P. Méndez, F. T. Flores, J. D. Martín, E. M. Rodríguez Rodríguez, and C. Díaz Romero, "Physicochemical characterization of cactus pads from Opuntia dillenii and Opuntia ficus indica," Food Chemistry, vol. 188, pp. 393-398, 2015.

[24] M. E. Rodríguez-García, C. de Lira, E. Hernández-Becerra et al., "Physicochemical characterization of nopal pads (Opuntia ficus indica) and dry vacuum nopal powders as a function of the maturation," Plant Foods for Human Nutrition, vol. 62, no. 3, pp. 107-112, 2007.

[25] C. Sáenz, E. Sepúlveda, N. Pak, and M. Lecaros, "Chemical and physical characterization of cactus cladode (Opuntia ficusindica) powder," Italian Journal of Food Science, vol. 22, no. 4, pp. 416-422, 2010.

[26] M. I. Hernández-Urbiola, M. Contreras-Padilla, E. PérezTorrero et al., "Study of nutritional composition of nopal (Opuntia ficus indica cv. Redonda) at different maturity stages," The Open Nutrition Journal, vol. 4, pp. 11-16, 2010.

[27] M. I. Hernández-Urbiola, E. Pérez-Torrero, and M. E. Rodríguez-García, "Chemical analysis of nutritional content of prickly pads (Opuntia ficus indica) at varied ages in an organic harvest," International Journal of Environmental Research and Public Health, vol. 8, no. 5, pp. 1287-1295, 2011.

[28] S. Murwan, A. Abdelwahab, and N. Sulafa, "Quality assessment of guar gum (endosperm) of guar (Cyamopsis tetragonoloba)," ISCA Journal of Biological Sciences, vol. 1, no. 1, pp. 67-70, 2012.

[29] F. Rincón, G. León de Pinto, O. Beltrán, C. Clamens, and R. Guerrero, "Funcionalidad de una mezcla de gomas de acacia glomerosa, enterolobium cyclocarpum e hymenaea courbaril en la preparación de helados de bajo contenido calórico," Revista Científica, vol. 18, pp. 87-92, 2008.

[30] P. K. Chityala, H. Khouryieh, K. Williams, and E. Conte, "Effect of xanthan/enzyme-modified guar gum mixtures on the stability of whey protein isolate stabilized fish oil-in-water emulsions," Food Chemistry, vol. 212, pp. 332-340, 2016.

[31] G. Tomás Ch, J. Huamán M, R. Aguirre M et al., "Estudio qímico y fitoquímico de la Opuntia ficus-indica "tuna", y elaboración de un alimento funcional," Revista Peruana de Química e Ingeniería Química, vol. 15, no. 1, article 5, 2012.

[32] M. M. Zhao, N. Yang, B. Yang, Y. Jiang, and G. Zhang, "Structural characterization of water-soluble polysaccharides from Opuntia monacantha cladodes in relation to their anti-glycated activities," Food Chemistry, vol. 105, no. 4, pp. 1480-1486, 2007.

[33] B. Smith, Infrared Spectral Interpretation: A Systematic Approach, CRS Press LLC, Boca Raton, Fla, USA, 1999.

[34] F. Nejatzadeh-Barandozi and S. T. Enferadi, "FT-IR study of the polysaccharides isolated from the skin juice, gel juice, and flower of Aloe vera tissues affected by fertilizer treatment," Organic and Medicinal Chemistry Letters, vol. 2, no. 1, article 33, 2012. 
[35] R. L. Whistler, Industrial Gums, Polysaccharides and Their Derivatives, Academic Press Inc, New York, NY, USA, 2nd edition, 1973.

[36] A. Abu Baker, A. Tahir, and M. K. Sabah Elkheir, "Effect of tree and nodule age on some physicochemical properties of gum from acacia senegal (1.) wild., Sudan," Research Journal of Agriculture and Biological Sciences, vol. 3, no. 6, pp. 866-870, 2007.

[37] R. M. A. Daoub, A. H. Elmubarak, M. Misran, E. A. Hassan, and M. E. Osman, "Characterization and functional properties of some natural Acacia gums," Journal of the Saudi Society of Agricultural Sciences, 2016.

[38] M. Libhaber and A. Orozco, Sustainable Treatment and Reuse of Municipal Wastewater, IWA Publishing, London, UK, 2012.

[39] A. A. Peláez-Cid, I. Velázquez-Ugalde, A. M. Herrera-González, and J. García-Serrano, "Textile dyes removal from aqueous solution using Opuntia ficus-indica fruit waste as adsorbent and its characterization," Journal of Environmental Management, vol. 130, pp. 90-97, 2013.

[40] Y. Anjaneyulu, N. Sreedhara Chary, and D. Samuel Suman Raj, "Decolourization of industrial effluents - Available methods and emerging technologies-A review," Reviews in Environmental Science and Biotechnology, vol. 4, no. 4, pp. 245-273, 2005.

[41] J. Zhang, F. Zhang, Y. Luo, and H. Yang, "A preliminary study on cactus as coagulant in water treatment," Process Biochemistry, vol. 41, no. 3, pp. 730-733, 2006. 

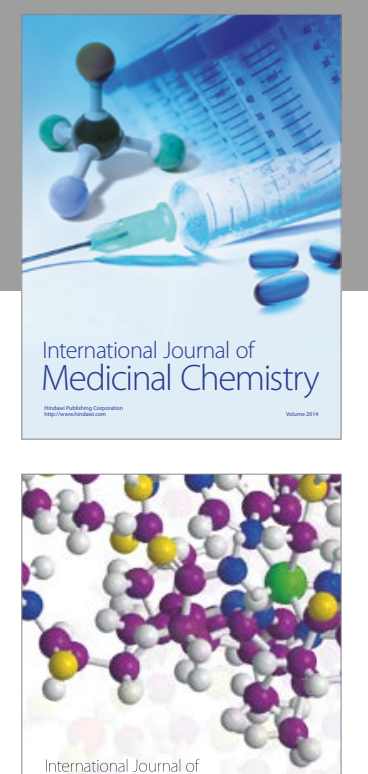

Carbohydrate Chemistry

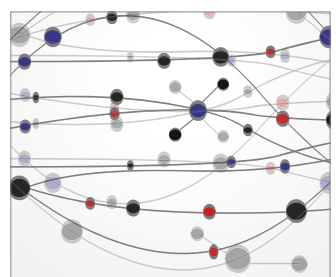

The Scientific World Journal
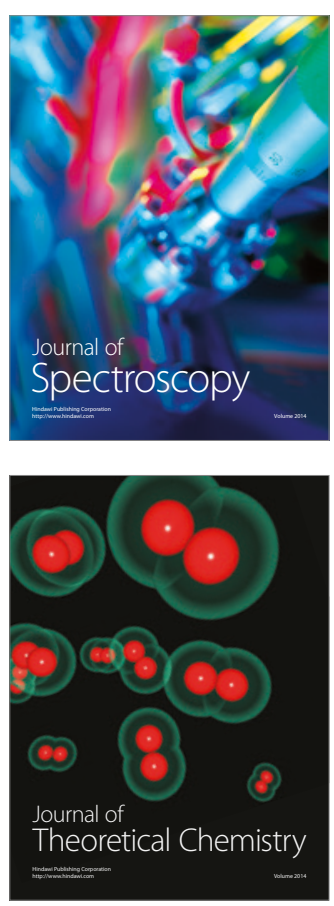
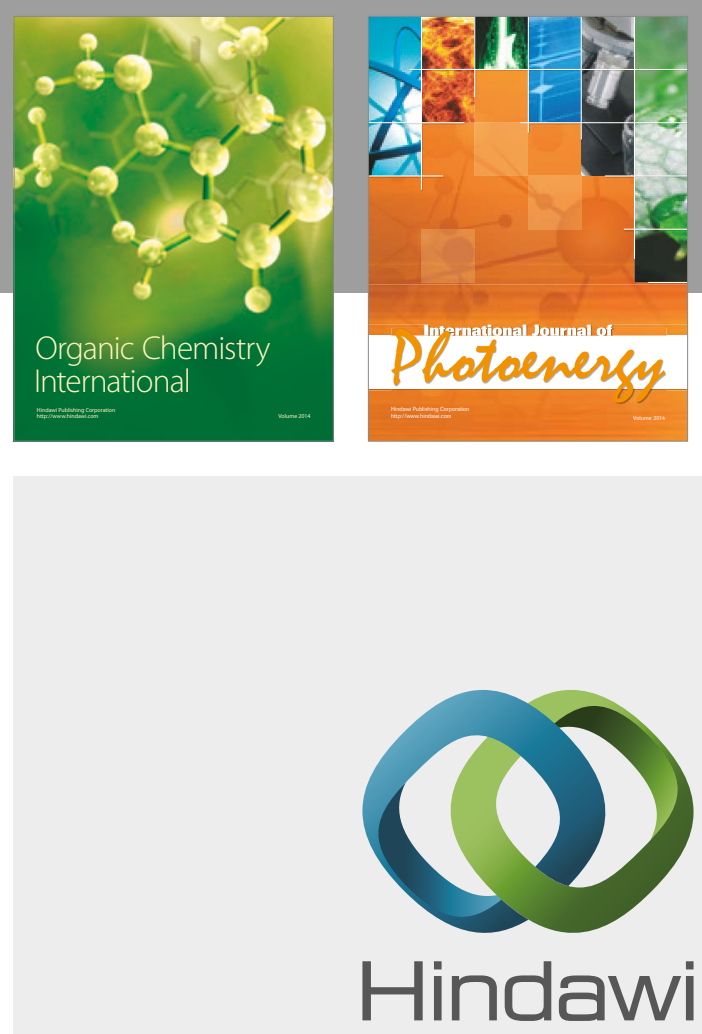

Submit your manuscripts at

https://www.hindawi.com

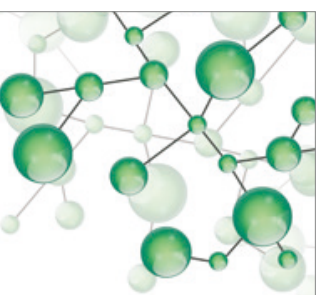

International Journal of

Inorganic Chemistry

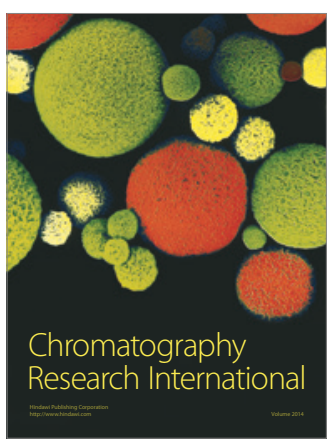

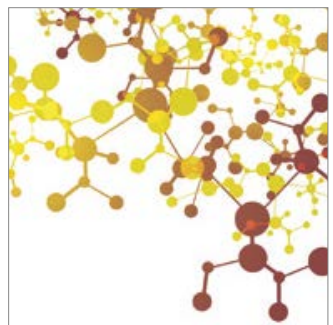

Applied Chemistry
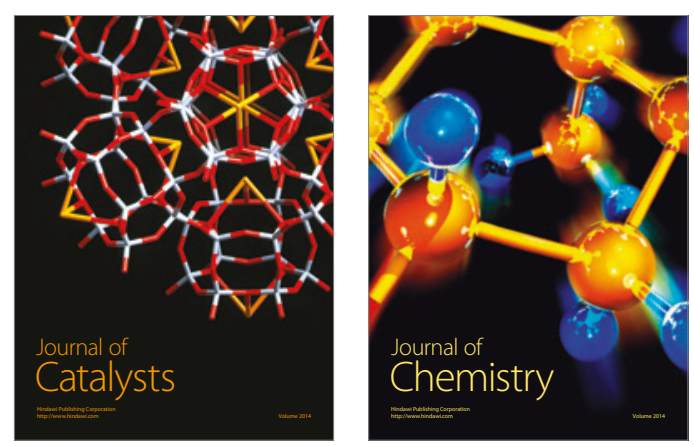
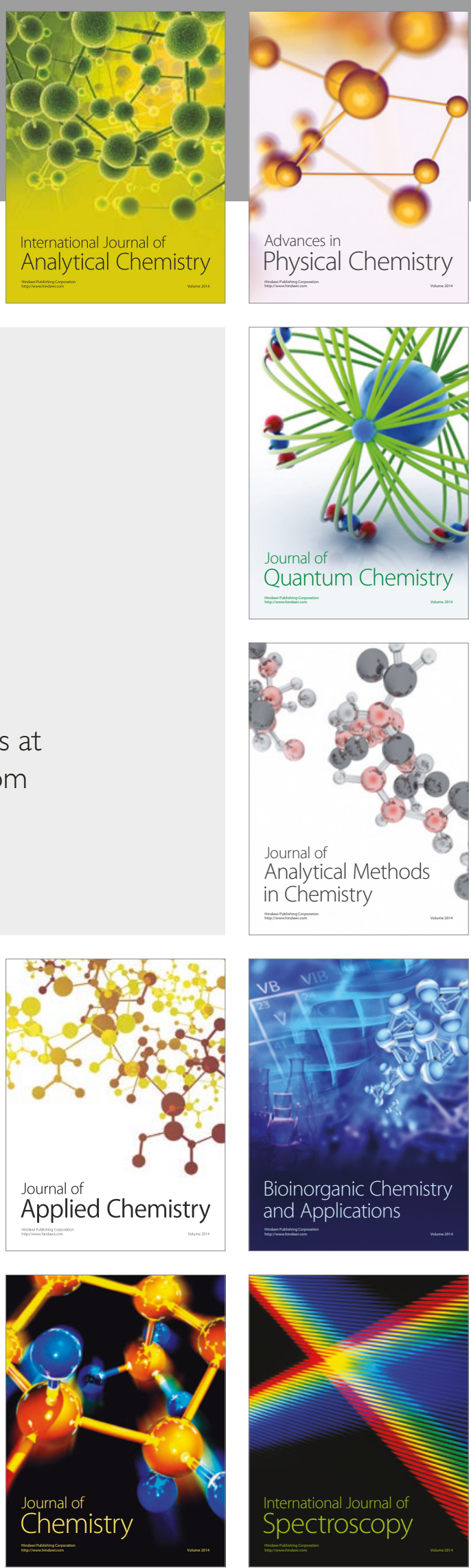